\title{
Splenic Burkitt Lymphoma
}

National Cancer Institute

\section{Source}

National Cancer Institute. Splenic Burkitt Lymphoma. NCI Thesaurus. Code C7309.

Burkitt lymphoma that involves the spleen. 